\title{
How the Lung Can Resist Edema Formation
}

\author{
Giuseppe Miserocchi* \\ Department of Medicine and Surgery, Università Milano Bicocca, Italy
}

Submission: February 18, 2017; Published: March 22, 2017

*Corresponding author: Giuseppe Miserocchi, Department of Medicine and Surgery, Università Milano Bicocca, Italy, Tel: +39335248452; Email: giuseppe.miserocchi@unimib.it

\section{Opinion}

One generally thinks of the lung as being an extremely fragile structure to accomplish its main job, namely to assure gas diffusion, for which an extremely thin air-blood barrier, about $0.3 \mu \mathrm{m}$ thick, is required. Yet, the idea of a delicate and fragile structure does not hold when thinking of another function of the lung, namely that of keeping the interstitial space and the alveoli "dry", thus preventing edema formation. From this stand point the lung appears quite a robust structure indeed. The pulmonary interstitum includes a fairly rigid fibrillar component (mostly collagen and elastin) and abundant "linking molecules" (from proteoglycan family) filling the frame of the fibrillary component, providing further rigidity to the lung tissue and keeping capillary permeability (the leakiness of the endothelium for water and solute) quite low [1]. A minimum volume of extravascular water is achieved by maintaining the pressure of the interstitial water at a sub-atmospheric pressure, about $-10 \mathrm{~cm} \mathrm{H}_{2} \mathrm{O}$ [2], reflecting the balance between extravascular fluid filtration and fluid drainage along pulmonary lymphatics. There is proof that lymphatics can indeed generate such negative pressure [3]. Fluid fluxes involved in these exchanges are incredibly low in physiological conditions, being in the range of $4 \cdot 10^{-8} /\left(\mathrm{cm}^{2} \cdot 24 \mathrm{~h}\right)$, about six order of magnitude $\left(10^{6}\right.$ !) less than oxygen diffusion fluxes. Minimal fluid exchanges reflect the very low permeability of pulmonary capillaries. Therefore, keeping water fluxes at minimum allows to optimize gas diffusion. How can then the lung maintain this condition when edemagenic conditions are established?

Edemagenic conditions occur:

a) When micro vascular permeability increases; this is the most common consequence of infectious and of "sterile" inflammation (widely overlooked) such as hypoxia exposure, surgery, trauma [4].

b) Lung over distension [5] as occurring during aggressive mechanical ventilation or re-expansion in the chest of a resected lung [6-8].

c) Increase in capillary pressure.
This last point has been frequently invoked based on wedge pressure measurements, but, as we shall see later, this occurs as a consequence of increased pulmonary vascular resistances due to capillary de-recruitment caused by developing edema [9].

Which mechanisms are then set in place by the lung to prevent edema formation?

i. The first, and most important, is the remarkable increase in interstitial pressure, from - 10 up to about $5 \mathrm{~cm} \mathrm{H}_{2} \mathrm{O}$ (so called "safety factor") that buffers further filtration in the initial phase of interstitial edema formation reflecting the remarkable rigidity of the tissue structure [10]. In fact, degradation and fragmentation of the macromolecular interstitial structure due to inflammation abolishes the "safety factor" and inevitably leads to severe edema [11-13].

ii. For reasons still largely unknown, edema formation in the lung is patchy, revealing different proneness to increase micro vascular filtration [14]. In regions where interstitial edema develops, the increase in interstitial pressure leads to compression of the capillary network [9]; since each unit of blood flow implies a corresponding unit of micro vascular filtration, this mechanical event evidently reduces filtration. It actually will favor reabsorption of interstitial fluid when capillary pressure approaches zero. Thus, controlling regional capillary blood flow allows, in turn, to control interstitial fluid balance. When blood flow is diverted from edematous to non edematous regions $[9,14]$ an increase in vascular resistances and in pulmonary artery pressure may occur due to a decrease in extension of perfused vascular bad.

iii. Vasoconstriction of pre-capillary arterioles [15] is a further mechanism occurring in edemagenic condition preventing the increase in capillary pressure.

All these mechanisms are set in place when the increase in extravascular water volume does not exceed 10\% [16]. In practice, lung extravascular water volume is so strictly controlled that it is difficult to detect initial deviations from the 
physiological state. As interstitial edema is on the edge between recovery and progression towards severe edema, it would be of great help to have a sensible diagnostic tool. CT scan fails to have a resolution to detect such a small increase in extravascular water; yet, evidence has been provided that measuring respiratory impedance by Forced Oscillation Technique might be a sensitive method to detect the early phase of developing edema $[17,18]$.

\section{References}

1. Miserocchi G (2009) Mechanisms controlling the volume of pleura fluid and extravascular lung water. Eur Respir Rev 18(114): 244-252.

2. Miserocchi G, Negrini D, Gonano C (1985) Direct measurement of interstitial pulmonary pressure in in situ lung with intact pleural space. J Appl Physiol 69(6): 2168-2174.

3. Miserocchi G, Mariani E, Negrini D (1982) Role of the diaphragm in setting liquid pressure in serous cavities. Respir Physiol 50(3): 381392

4. Andersson U, Tracey KJ (2011) HMGB1 Is a Therapeutic Target for Sterile Inflammation and Infection. Annu Rev Immunol 29: 139-162.

5. Miserocchi G, Negrini D, Gonano C (1985) Parenchymal stress affects interstitial and pleural pressures in in situ lung. J Appl Physiol 71(5): 1967-1972.

6. Salito C, Bovio D, Orsetti G, Salati M, Brunelli A, et al. (2016) Effect of lung resection on pleuro-pulmonary mechanics and fluid balance. Respir Physiol Neurobiol 221: 35-40.

7. Pompili C, Miserocchi G (2016) Air leak after lung resection: pathophysiology and patients implications. J Thorac Dis 8(Suppl 1): S46-S54.

8. Miserocchi G, Beretta E, Rivolta I (2010) Respiratory mechanics and fluid dynamics after lung resection surgery. Thorac Surg Clin 20(3): 345-357.
9. Mazzuca E, Aliverti A, Miserocchi G (2016) Computational micro-scale model of control of extravascular water and capillary perfusion in the air blood barrier. J Theor Biol 400: 42-51.

10. Miserocchi G, Negrini D, Del Fabbro M, Venturoli D (1993) Pulmonary interstitial pressure in intact in situ lung: the transition to interstitial edema. J Appl Physiol 74(3): 1171-1177.

11. Miserocchi G, Negrini D, Passi A, De Luca G (2001) Development of lung edema: interstitial fluid dynamics and molecular structure. News Physiol Sci 16: 66-71.

12. Miserocchi G, Passi A, Negrini D, Del Fabbro M, De Luca G (2001) Pulmonary interstitial pressure and tissue matrix structure in acute hypoxia. Am J Physiol Lung Cell Mol Physiol 280(5): L881-L887.

13. Moriondo A, Pelosi P, Passi A, Viola M, Marcozzi C, et al. (1985) Proteoglycan fragmentation and respiratory mechanics in mechanically ventilated healthy rats. J Appl Physiol 103(3): 747-756.

14. Rivolta I, Lucchini V, Rocchetti M, Kolar F, Palazzo F, et al. (2011) Interstitial pressure and lung oedema in chronic hypoxia. Eur Respir J 37(4): 943-949.

15. Negrini D (1995) Pulmonary microvascular pressure profile during development of hydrostatic edema. Microcirculation 2(2): 173-180.

16. Miserocchi G, Rivolta I (2012) Mechanistic Considerations on the Development of Lung Edema: Vascular, Perivascular and Molecular Aspects from Early Stage to Tissue and Vascular Remodeling. Current Respiratory Medicine Reviews 8(2): 82-89.

17. Dellacà RL, Zannin E, Sancini G, Rivolta I, Leone BE, et al. (2008) Changes in the mechanical properties of the respiratory system during the development of interstitial lung edema. Respir Res 9: 51.

18. Bartesaghi M, Beretta E, Pollastri L, Scotti V, Mandolesi G, et al. (2014) Inter-individual differences in control of alveolar capillary blood volume in exercise and hypoxia. Respir Physiol Neurobiol 190: 96-104.

This work is licensed under Creative Commons Attribution 4.0 License

DOI: 10.19080/JOCCT.2017.03.555625

\section{Your next submission with Juniper Publishers} will reach you the below assets

- Quality Editorial service

- Swift Peer Review

- Reprints availability

- E-prints Service

- Manuscript Podcast for convenient understanding

- Global attainment for your research

- Manuscript accessibility in different formats

( Pdf, E-pub, Full Text, Audio)

- Unceasing customer service

Track the below URL for one-step submission https://juniperpublishers.com/online-submission.php 